Journal of Applied Fluid Mechanics, Vol. 1, No. 2, pp. 17-23, 2008.

Available online at www.jafmonline.net, ISSN 1735-3572, EISSN 1735-3645.

DOI: $10.36884 / \mathrm{jafm} .1 .02 .11844$

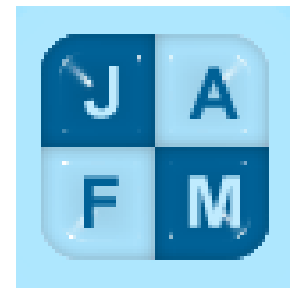

\title{
Application of the Modified Log-Wake Law in Open-Channels
}

\author{
Junke Guo $^{1}$ and Pierre Y. Julien ${ }^{2}$ \\ ${ }^{1}$ Department of Civil Engineering, University of Nebraska, Omaha, NE 68182-0178, USA \\ ${ }^{2}$ Department of Civil Engineering, Colorado State University, Fort Collins, CO 68135, USA \\ Email:jguo2@unl.edu
}

(Received December 4, 2006; accepted August 7, 2007)

\begin{abstract}
The modified log-wake law, which was developed for turbulent boundary layers and pipe flows, is extended to turbulent flows in open-channels. Turbulent velocity profiles in open-channels can be approximated with three components: (1) the law of the wall that results from the constant bed shear stress; (2) the law of the wake that reflects the effects of gravity, secondary currents and bed roughness; and (3) the cubic correction near the maximum velocity. A procedure to determine the four model parameters from velocity measurements while keeping $\kappa=0.41$ is presented. The modified log-wake law compares very well with experimental data from Coleman, Lyn, Kironoto and Graf and Sarma et al. It also replicates the measured velocity profiles of the Mississippi River. In particular, it can well fit the velocity dip phenomenon in openchannels where the conventional log-wake law fails.
\end{abstract}

Keywords: Open channel flow, turbulence, velocity dip phenomenon, velocity distribution, velocity profile.

\section{NOMENCLATURE}

$\begin{array}{ll}a, b, c & \text { fitting parameters of the parabolic law } \\ B & \text { additive constant of the log law } \\ \mathrm{Fr} & \text { Froude number } \\ h & \text { flow depth } \\ k_{s} & \text { Nikuradse roughness height } \\ \operatorname{Re} & \text { Reynolds number } \\ y & \text { distance from the bed } \\ y_{i} & \text { discrete distance from the bed } \\ y_{0} & \text { zero-velocity position over rough bed } \\ p & \text { MatLab fitting parameter } \\ S & \text { channel slope } \\ T & \text { Temperature }\end{array}$

\section{INTRODUCTION}

Field measurements showed that most natural river flows are three-dimensional due to the presence of large-scale free-surface secondary currents (Nezu, Tominaga and Nakagawa 1993). The measured maximum velocity usually appears below the free surface at a distance of 0.05 to 0.5 of the flow depth (Chow 1959, p.24; Cheng and Gartner 2003; Moramarco et al. 2004), which is called the velocity dip phenomenon. Modeling the dip phenomenon is significant for establishing stage-discharge relationships and for the vertical average velocity time-averaged velocity at a distance $y$ time-averaged velocity at a distance $y_{i}$ maximum velocity at $y=\delta$

$u_{*} \quad$ shear velocity

$W \quad$ channel width

$\delta \quad$ dip distance from the bed

$\kappa \quad$ von Karman constant

$v \quad$ kinematic viscosity of water

$\Pi \quad$ Coles wake strength

$\xi \quad$ normalized distance, $\xi=y / \delta$ analysis of resistance to flow and contaminant transport. It is also important to define the relationship between surface and mean flow velocities (Lee and Julien 2006).

Previous studies focused primarily on two-dimensional flows where secondary currents can be neglected and the maximum velocity occurs at the free surface. For such flows, velocity profiles can be approximated by the conventional log law or the log-wake law (Steffler et al. 1985; Nezu and Rodi 1986; Kirkgoz 1989; Cardoso et al. 1989; Kironoto and Graf 1994; Muste and Patel 1997). 
By contrast, although the velocity dip phenomenon has been reported for a long time (Leighly 1932), our understanding of it is poor and only a few studies on it can be found in the literature (Sarma et al. 1983, 2000; Chiu and Said 1995; Chiu and Tung 2002; Moramarco et al. 2004; Guo and Julien 2001). The velocity dip phenomenon can hardly be modeled with log-wake velocity profiles because it imposes a velocity increase with distance from the boundary.

Recently, Guo and Julien (2003) and Guo et al. (2005) proposed a modified log-wake law (MLWL) that well represents experimental data in pipes and zero-pressuregradient (ZPG) boundary layers. Since open-channel flows associated with the dip phenomenon are similar to those in pipes and boundary layers where a zero velocity gradient exists at the maximum velocity, the objective of this paper is to extend the MLWL to open-channels associated with the velocity dip phenomenon.

\section{THE MODIFIED LOG-WAKE LAW (MLWL)}

According to Guo and Julien (2003) and Guo et al. (2005), the modified log-wake law reads

$$
\frac{u}{u_{*}}=\left(\frac{1}{\kappa} \ln \frac{y u_{*}}{v}+B\right)+\frac{2 \Pi}{\kappa} \sin ^{2} \frac{\pi \xi}{2}-\frac{\xi^{3}}{3 \kappa}
$$

where $u=$ time-averaged velocity in the flow direction, $u_{*}=$ shear velocity, $\kappa=$ von Karman constant, $y=$ distance from the wall, $v=$ kinematic viscosity of the fluid, $B=$ additive constant that relates to the wall roughness, $\Pi=$ Coles wake strength, and $\xi=$ normalized distance relative to the dip position $\delta$. The terms in parentheses are the logarithmic law of the wall; the sine-square term is the law of the wake that expresses the effects of the constant pressure-gradient in pipes or the convective inertia in ZPG boundary layers; and the cubic function forces the log law gradient to be zero at the maximum velocity.

\section{TEST WITH FLUME DATA}

\subsection{DETERMINATION OF THE MODEL PARAMETERS}

For convenience, we replace the additive constant $B$ in Eq. (1) with the maximum velocity $u_{\max }$, i.e.

$$
\frac{u_{\max }-u}{u_{*}}=-\frac{1}{\kappa} \ln \xi+\frac{2 \Pi}{\kappa} \cos ^{2} \frac{\pi \xi}{2}-\frac{1-\xi^{3}}{3 \kappa}
$$

By convention, we assume $\kappa=0.41$ in this paper, thus leaving four parameters to be determined from a measured velocity profile. We need to know the parameters $u_{\max }, u_{*}, \delta$ and $\Pi$ to plot a profile. Note that $\delta$ is embedded in $\xi$.

Since the MLWL reduces to a parabolic law near the point of maximum velocity (Guo and Julien 2003), we assume

$$
u=a y^{2}+b y+c
$$

for data with $\xi=y / \delta>0.6$, where $a, b$ and $c$ are fitting parameters. Equation (3) gives the dip position at

$$
\delta=-\frac{b}{2 a}
$$

and the maximum velocity

$$
u_{\max }=c-\frac{b^{2}}{4 a}
$$

We then normalize the distance $y$ as $\xi=y / \delta$. Applying Eq. (2) to data with $\xi<0.2$ gives the law of the wall,

$$
u=\frac{u_{*}}{\kappa} \ln \xi+B u_{*}
$$

where

$$
B u_{*}=u_{\max }-\frac{u_{*}}{\kappa}\left(2 \Pi-\frac{1}{3}\right)
$$

We can get the shear velocity $u_{*}$ from the slope $u_{*} / \kappa$ and the wake strength $\Pi$ from the intercept $B u_{*}$. The data sets of Coleman (1986), Lyn (1986), Kironoto and Graf (1994), and Sarma et al. (2000) are used to test the MLWL and the above procedures.

\subsection{DATA ANALYSIS}

Coleman's (1986) data are widely used in the literature. The three clear water runs (Runs 1, 21 and 32) are used in this analysis. To illustrate the above procedures, take RUN 1 for an example. The measured velocity profile data and corresponding positions are:

$$
\begin{aligned}
u_{i}= & (0.709,0.773,0.823,0.849,0.884,0.927, \ldots \\
& 0.981,1.026,1.054,1.053,1.048,1.039) ; \\
y_{i}= & (6,12,18,24,30,46,69,91,122,137, \ldots \\
& 152,162) ;
\end{aligned}
$$

where $u_{i}$ is in $\mathrm{m} / \mathrm{s}$ and $y_{i}$ in $\mathrm{mm}$. We can see that the dip position is at about $y=122 \mathrm{~mm}$ corresponding to the velocity $u=1.054 \mathrm{~m} / \mathrm{s}$. To accurately locate the maximum velocity, we fit the last 6 data to the parabolic law, Eq. (3), which gives the dip position $\delta=132 \mathrm{~mm}$ from Eq. (4) and the maximum velocity $u_{\max }=1.056 \mathrm{~m} / \mathrm{s}$ from Eq. (5). The distance $y_{\mathrm{i}}$ is then normalized by $\delta$. The first 4 data satisfy the condition $\xi_{l}=y_{i} / \delta<0.2$ and are used to fit the log law, Eq. (6). The slope $u * \kappa$ and intercept $B u *$ are found to be 0.1024 and 1.0235 , respectively. Assuming $\kappa=0.41$, the shear velocity is then $u_{*}=0.042 \mathrm{~m} / \mathrm{s}$ and the wake strength from Eq. (7) is $\Pi=0.323$, which is larger than 0.19 obtained by Coleman (1986). This difference is due to the cubic correction term at the maximum velocity. The experimental and calculated model parameters for the three clear water runs are tabulated in Table 1; and the comparison of the MLWL with the experimental data is plotted in Fig.1, where Fig. 1a is in rectangular coordinates and Fig. $1 \mathrm{~b}$ in semilog plot. 
Junke Guo and Pierre Y. Julien / JAFM , Vol. 1, No. 2, pp. 17-23, 2008.

Similarly, we list the parameters of experiments of Lyn $(1986,2000)$ in Table 1, and Kironoto and Graf (1994) as well as Sarma et al. (2000) in Table 2. The corresponding comparisons are shown in Figs. 2, 3 and 4, respectively. All the four data sets confirm the functional structure of the MLWL. However, from Tables 1 and 2, we can see that the wake strength varies between 0 and 0.48 . This means a universal wake strength $\Pi$ does not exist in open-channel flows, unlike ZPG boundary layers and pipe flows.

Table 1- Experimental and calculated parameters of Coleman and Lyn

\begin{tabular}{lccccccc}
\hline \multirow{2}{*}{\begin{tabular}{c} 
Data set \\
\cline { 2 - 8 }$(1)$
\end{tabular}} & \multicolumn{3}{c}{ Coleman (1986) } & \multicolumn{4}{c}{ Lyn (1986) } \\
\cline { 2 - 8 } & RUN1 & RUN21 & RUN32 & C1 & C2 & C3 & C4 \\
& $(2)$ & $(3)$ & $(4)$ & $(5)$ & $(6)$ & $(7)$ & $(8)$ \\
\hline$S\left(\times 10^{-3}\right)$ & 2 & 2 & 2 & 2.06 & 2.70 & 2.96 & 4.01 \\
$T\left({ }^{\circ} \mathrm{C}\right)$ & 21.1 & 23.8 & 21.7 & 18.7 & 21.3 & 21.0 & 21.3 \\
$h(\mathrm{~m})$ & 0.172 & 0.169 & 0.173 & 0.0654 & 0.0653 & 0.0575 & 0.0569 \\
$U(\mathrm{~m} / \mathrm{s})$ & 1.02 & 1.02 & 0.995 & 0.658 & 0.772 & 0.734 & 0.868 \\
$\mathrm{Re}=4 h U / v\left(\times 10^{5}\right)$ & 7.01 & 7.41 & 7.02 & 1.63 & 2.04 & 1.69 & 1.99 \\
$\mathrm{Fr}=U /(g h)^{1 / 2}$ & 0.785 & 0.792 & 0.764 & 0.82 & 0.97 & 0.97 & 1.16 \\
\hline$W / h$ & 2.07 & 2.11 & 2.06 & 4.08 & 4.09 & 4.64 & 4.69 \\
$\delta, \mathrm{m}$, from $(4)$ & 0.132 & 0.126 & 0.128 & 0.0572 & 0.0522 & 0.0553 & 0.0486 \\
$u_{\mathrm{max}}, \mathrm{m} / \mathrm{s}$, from $(5)$ & 1.056 & 1.049 & 1.026 & 0.752 & 0.875 & 0.858 & 1.018 \\
$u_{*}, \mathrm{~m} / \mathrm{s}$, from $(6)$ & 0.042 & 0.038 & 0.038 & 0.034 & 0.036 & 0.037 & 0.044 \\
$\Pi$, from $(7)$ & 0.323 & 0.352 & 0.481 & 0.229 & 0.318 & 0.292 & 0.339 \\
$\delta / h$ & 0.766 & 0.745 & 0.742 & 0.875 & 0.800 & 0.961 & 0.855 \\
\hline \hline
\end{tabular}

Table 2- Experimental and calculated parameters of Kironoto and Graf, and Sarma et al.

\begin{tabular}{|c|c|c|c|c|c|c|c|c|c|}
\hline \multirow[b]{2}{*}{$\begin{array}{c}\text { Data set } \\
\text { (1) }\end{array}$} & \multicolumn{4}{|c|}{ Kironoto and Graf (1994) } & \multicolumn{5}{|c|}{ Sarma, Prasad and Sarma (2000) } \\
\hline & $\begin{array}{l}\text { UGA3 } \\
\text { (2) }\end{array}$ & $\begin{array}{l}\text { UGA5 } \\
\text { (3) }\end{array}$ & $\begin{array}{c}\text { UGB3 } \\
\text { (4) }\end{array}$ & $\begin{array}{l}\text { UGB5 } \\
\text { (5) }\end{array}$ & $\begin{array}{c}A \\
(6) \\
\end{array}$ & $\begin{array}{c}\text { B } \\
(7) \\
\end{array}$ & $\begin{array}{c}C \\
(8) \\
\end{array}$ & $\begin{array}{c}\mathrm{D} \\
(9) \\
\end{array}$ & $\begin{array}{c}E \\
(10) \\
\end{array}$ \\
\hline$S\left(\times 10^{-3}\right)$ & 0.25 & 0.25 & 0.5 & 0.5 & & & & & \\
\hline$T\left({ }^{\circ} \mathrm{C}\right)$ & 23 & 23 & 23 & 23 & \multicolumn{5}{|c|}{20} \\
\hline$h(\mathrm{~m})$ & 0.285 & 0.285 & 0.290 & 0.290 & \multicolumn{5}{|c|}{$0.35 \& 1.85$} \\
\hline$U(\mathrm{~m} / \mathrm{s})$ & 0.503 & 0.502 & 0.405 & 0.396 & \multicolumn{5}{|c|}{1.364 to 1.92} \\
\hline $\operatorname{Re}=4 h U / V\left(\times 10^{5}\right)$ & 57.3 & 57.2 & 47.0 & 46.3 & \multicolumn{5}{|c|}{1.44 to 8.3} \\
\hline $\mathrm{Fr}=U /(g h)^{1 / 2}$ & 0.3 & 0.3 & 0.23 & 0.23 & 1.88 & 1.94 & 1.57 & 1.57 & 1.57 \\
\hline$W / h$ & 2.11 & 2.11 & 2.07 & 2.07 & \multicolumn{5}{|c|}{4.11 to 15.64} \\
\hline$\delta, \mathrm{m}$ & 0.214 & 0.214 & 0.215 & 0.248 & & & & & \\
\hline$u_{\max }, \mathrm{m} / \mathrm{s}$ & 0.571 & 0.571 & 0.465 & 0.463 & 1.852 & 2.108 & 2.126 & 2.363 & 1.761 \\
\hline$u_{*}, \mathrm{~m} / \mathrm{s}$ & 0.038 & 0.041 & 0.033 & 0.035 & 0.086 & 0.099 & 0.133 & 0.174 & 0.133 \\
\hline$\Pi$ & 0.175 & 0.114 & 0.197 & 0.134 & 0.180 & 0.201 & 0.209 & 0.048 & 0 \\
\hline$\delta / h$ & 0.753 & 0.753 & 0.741 & 0.855 & 0.949 & 1 & 0.679 & 0.839 & 0.535 \\
\hline
\end{tabular}
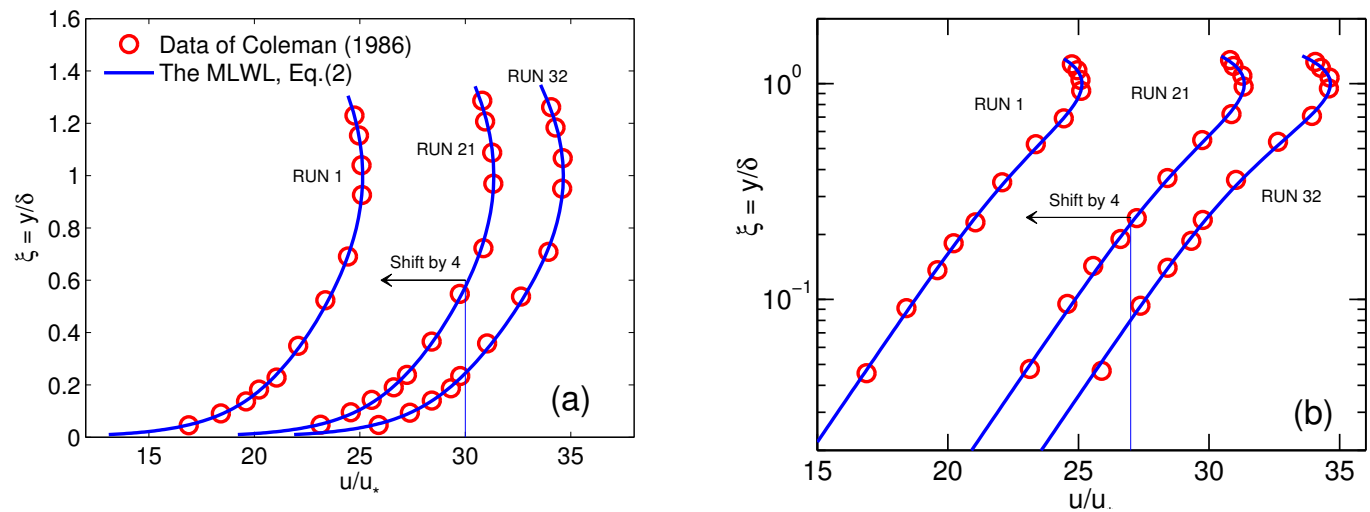

Fig. 1- Comparison of the MLWL with Coleman's data set 

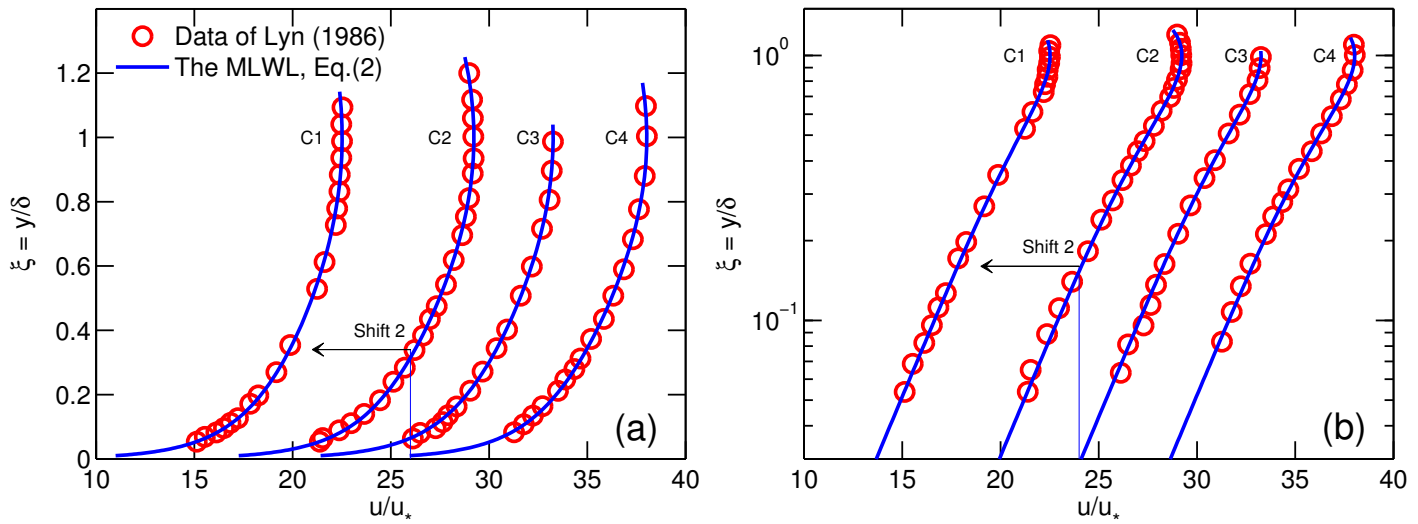

Fig. 2- Comparison of the MLWL with Lyn's data set
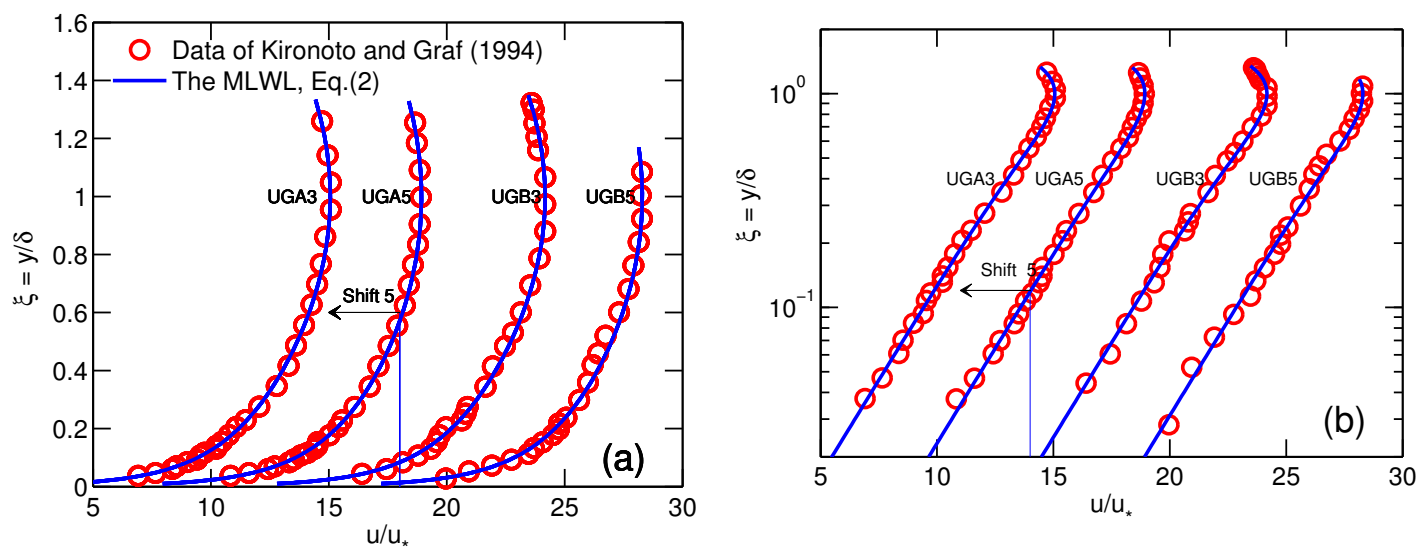

Fig. 3- Comparison of the MLWL with Kironoto and Graf's data set
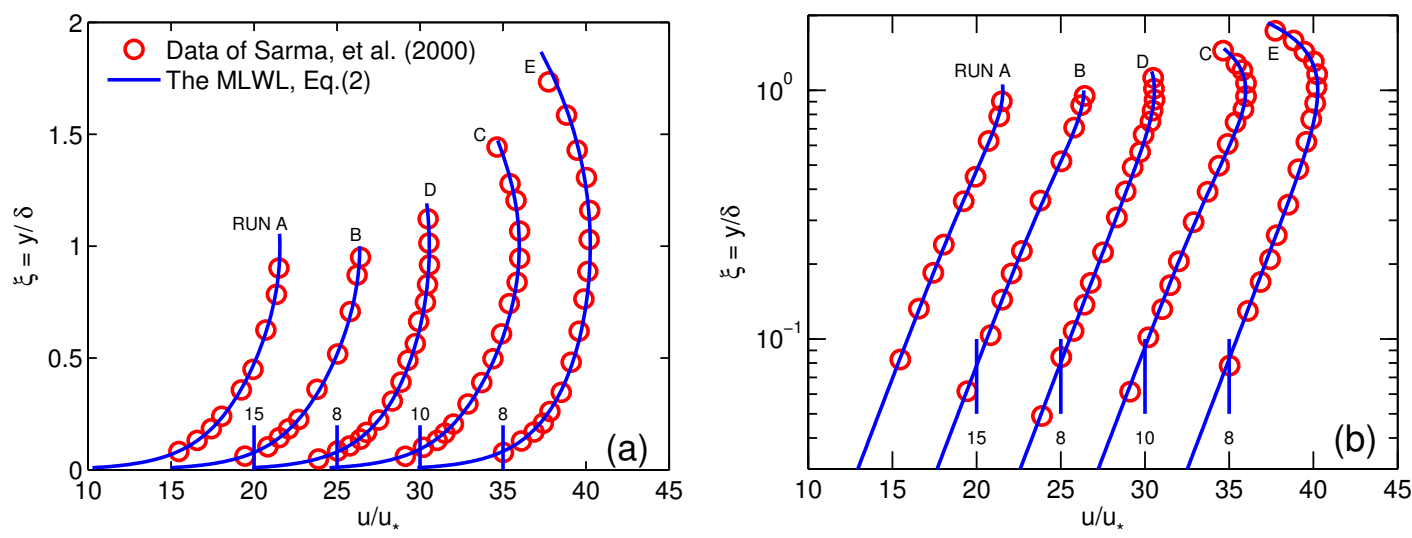

Fig. 4- Comparison of the MLWL with Sarma's data set. 
Junke Guo and Pierre Y. Julien / JAFM , Vol. 1, No. 2, pp. 17-23, 2008.

\section{APPLICATION TO FIELD MEASUREMENTS}

Although a universal value of $\Pi$ does not exist, the MLWL has a clear application in flow measurements. Given a few sampled velocities, it can provide the vertical average velocity with dip phenomenon. Figure 5 defines the theoretical bed in natural rivers.

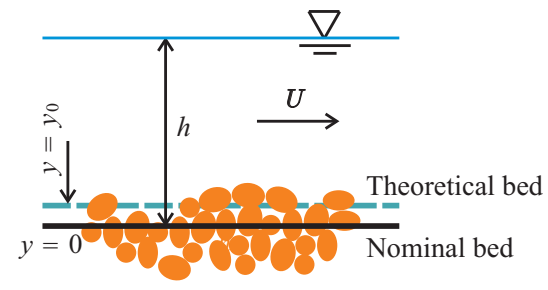

(a) Non-uniform roughness

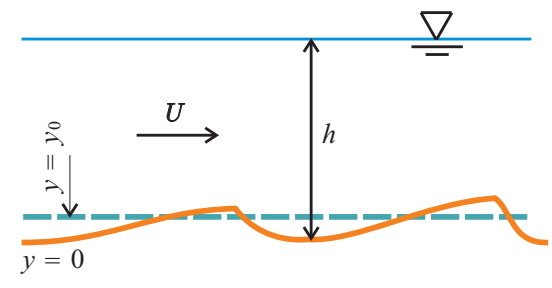

(b) Channel with bedforms

Fig. 5- Scheme of theoretical bed in field measurements

Referring to Fig. 5, we can rewrite Eq. (1) as

$u=\frac{u_{*}}{\kappa}\left[\ln \frac{y}{y_{0}}-\frac{1}{3}\left(\frac{y-y_{0}}{\delta-y_{0}}\right)^{3}\right]+\frac{2 \Pi u_{*}}{\kappa} \sin ^{2} \frac{\pi\left(y-y_{0}\right)}{2\left(\delta-y_{0}\right)}$

in which $y$ is based on an arbitrary vertical coordinate and $y_{0}$ is the theoretical bed where the velocity $u$ is zero. Note that the constant $B$ in Eq. (1) or the maximum velocity $u_{\max }$ in Eq. (2) has been included in the value $y_{0}$ in Eq. (8). Given measurements $\left(y_{i}, u_{i}\right)$, assuming $\kappa=0.41$, we have four fitting parameters, $u * y_{0}, \delta$, and $\Pi$. Let

$$
\begin{aligned}
& p(1)=u_{*} / \kappa, p(2)=y_{0} \\
& p(3)=\delta, p(4)=2 \Pi u_{*} / \kappa
\end{aligned}
$$

the four parameters can be fitted using a nonlinear optimization program. For example, with MatLab the parameters can be found by the following functions:

$$
\begin{aligned}
& \text { fun }=\text { inline }(\text { 'p }(1) *(\log (\mathrm{zi} . / \mathrm{p}(2))-\ldots \\
& \left.((\mathrm{zi}-\mathrm{p}(2)) . /(\mathrm{p}(3)-\mathrm{p}(2))))^{\wedge} 3 \cdot / 3\right)+\ldots \\
& \mathrm{p}(4) . * \sin (\mathrm{pi} . *(\mathrm{zi}-\mathrm{p}(2)) . / 2 . /(\mathrm{p}(3)-\ldots \\
& \mathrm{p}(2))) . \wedge 2 \text { ','p','zi'); } \\
& \text { p = lsqcurvefit(fun, [p10 p20 p30 p40], zi, ui); }
\end{aligned}
$$

in which $[\mathrm{p} 10, \mathrm{p} 20, \mathrm{p} 30, \mathrm{p} 40]$ are initial values of the optimization. The four parameters are then obtained from Eq. (9). Furthermore, we can get the maximum velocity

$$
u_{\max }=\frac{u_{*}}{\kappa}\left(\ln \frac{\delta}{y_{0}}+2 \Pi-\frac{1}{3}\right)
$$

Integrating Eq. (8) between $y_{0}$ and $h$ and divided by $h-y_{0}$ gives the vertical average velocity

$$
\begin{aligned}
U=\frac{u_{*}}{\kappa} & {\left[\frac{h}{h-y_{0}} \ln \frac{h}{y_{0}}-\frac{\Pi}{\pi} \frac{\delta-y_{0}}{h-y_{0}} \sin \frac{\pi\left(h-y_{0}\right)}{\left(\delta-y_{0}\right)}\right.} \\
& \left.-\frac{1}{12}\left(\frac{h-y_{0}}{\delta-y_{0}}\right)^{3}+\Pi-1\right]
\end{aligned}
$$

For $h>>y_{0}$ and $\delta>>y_{0}$, the above can be simplified as

$$
U=\frac{u_{*}}{\kappa}\left[\ln \frac{h}{y_{0}}-\frac{\Pi}{\pi} \frac{\delta}{h} \sin \frac{\pi h}{\delta}-\frac{1}{12}\left(\frac{h}{\delta}\right)^{3}+\Pi-1\right]
$$

Application to a Mississippi River velocity profile measurement: Figure 6 shows a velocity profile measurement on a vertical that is situated at the deepest location in a channel section of the Mississippi River (Chiu and Said 1995; Gordon 1992). Fitting Eq. (8) to the measured data and applying the above MatLab functions, we obtain: $u_{*}=0.121 \mathrm{~m} / \mathrm{s}, y_{0}=0.335 \mathrm{~m}, \delta=22.2 \mathrm{~m}$, and $\Pi=-0.002$. The maximum velocity from Eq. (10) is $u_{\max }=1.12 \mathrm{~m} / \mathrm{s}$, and the average velocity is $U=0.973 \mathrm{~m} / \mathrm{s}$ from Eq. (11) while $0.960 \mathrm{~m} / \mathrm{s}$ from Eq. (12). The theoretical bed $y_{0}$ relates to the equivalent Nikuradse roughness $k_{s}$ given $k_{s}=30 y_{0}$, which gives $k_{s}=10 \mathrm{~m}$ that is definitely unreasonable and implies bed forms exist. The dip position $\delta$ is located at about a third of water depth below the free surface. The comparison in Fig. 6 shows excellent agreement between the MLWL and the real velocity distribution measurements.

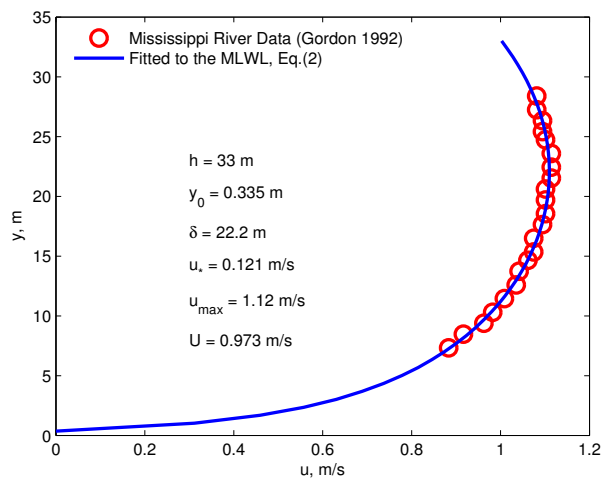

Fig. 6- A velocity profile in Mississippi River

Note that unlike flume experiments, this field data set shows negative wake strength, which is close to zero and should be considered negligible compared to the values listed in Tables 1 and 2. 
Junke Guo and Pierre Y. Julien / JAFM , Vol. 1, No. 2, pp. 17-23, 2008.

\section{CONCLUSIONS}

The following conclusions can be drawn from the above analysis:

1) The modified log-wake law (MLWL) can be applied to describe turbulent velocity profiles in open-channel flows.

2) Besides the von Karman constant $\kappa=0.41$, the MLWL includes four additional model parameters: (i) the dip position $\delta$ from the bed; (ii) the bed shear velocity $u_{*}$; (iii) the wake strength $\Pi$; and (iv) either the integration constant $B$, the maximum velocity $u_{\max }$, or the theoretical bed elevation $y_{0}$ for rough channels.

3) The MLWL compares very well with flume data from Coleman (1986), Lyn (1986), Kironoto and Graf (1994) and Sarma et al. (2000). In particular, it can well fit the velocity dip phenomenon near the free surface.

4) A procedure of applying the MLWL to field measurements is proposed. The application to a Mississippi River velocity profile measurement shows a good agreement between the MLWL and the field data.

In general, the empirical procedure to determine the four parameters of the modified log-wake law (MLWL) results in excellent profiles compared with laboratory and field measurements. Except for the von Karman constant set at $\kappa=0.41$, the model does not yield universal values of the four other model parameters for generalized predictive purposes.

\section{ACKNOWLEDGEMENTS}

The authors are grateful to Dr. D. A. Lyn at Purdue University, Dr. M. Muste at the University of Iowa, and Dr. W. Graf at the Swiss Federal Institute of Technology at Lausanne for providing their laboratory experimental data for this study. This study was supported by the University of Nebraska Academic Research Fund under Grant No. 27 1120-0005-002 for the first author.

\section{REFERENCES}

Cardoso, A. H., Graf, W. H. and Gust, G. (1989). "Uniform flow in smooth open-channel." J. Hydr. Res., IAHR, 27(5), 603-616.

Cheng, R. T., and Gartner, J. W. (2003). "Complete velocity distribution in river cross-sections measured by acoustic instruments." Proceedings of the IEEE/OESS 7th Working Conference on Current Measurement Technology, San Diego, CA, March 13-15, 2003, p. 21-26.
Chiu, C. L. and Said, C. A. A. (1995). Maximum and mean velocities and entropy in open-channel flow. $J$. Hydr. Engrg., ASCE, 121(1), 26-35.

Chiu, C. L. and Tung, N. C. (2002). Maximum velocity and regularities in open-channel flow. J. Hydr. Engrg., ASCE, 128(4), 390-398.

Chow, V. T. (1959). Open-Channel Hydraulics. McGrawHill, 680p.

Coleman, N. L. (1986). Effects of suspended sediment on the open-channel velocity distribution. Water Resources Research, AGU, 22(10), 1377-1384.

Gordon, L. (1992). Mississippi river discharge. RD Instruments, San Diego, CA.

Guo, J. and Julien, P. Y. (2001). Turbulent velocity profiles in sediment-laden flows. J. Hydr. Res., IAHR, 39(1), 11-23.

Guo, J. and Julien, P. Y. (2003). Modified log-wake law for turbulent flows in smooth pipes. J. Hydr. Res., IAHR, 41(5), 493-501.

Guo, J., Julien, P. Y. and Meroney, R, N. (2005). Modified Log-Wake Law in Zero-Pressure-Gradient Turbulent Boundary Layers. J. of Hydr. Research, IAHR, 43(4), 421-430.

Kirkgoz, S. (1989). Turbulent velocity profiles for smooth and rough open-channel flow. J. Hydr. Engrg., ASCE, 115(11), 1543-1561.

Kironoto, B. A. and Graf, W. H. (1994). Turbulence characteristics in rough uniform open-channel flow. Proc. Instn Civ. Engrs Wat. Marit. \& Energy, 106(12), 333-344.

Lee, J.S. and P.Y. Julien (2006). Electromagnetic Wave Surface Velocimetry. J. Hydr. Engrg., ASCE, 132(2), 146-153.

Leighly, J. B. (1932). Toward a theory of the morphologic significance of turbulence in the flow of water in streams. University of California Publications in Geography, 6(1), 1-22, Cambridge University Press.

Lyn, D. A. (1986). Turbulence and Turbulent Transport in Sediment-Laden Open-Channel Flows. W. M. Keck Laboratory of Hydraulics and Water Resources, California Institute of Technology, Pasadena, CA.

Lyn, D. A. (2000). Regression Residuals and mean profiles in uniform open-channel flows. J. Hydr. Engrg., ASCE, 126(1), 24-32.

Moramarco, T., Saltalippi and Singh, V. P. (2004). Estimation of mean velocity in natural channels based on Chiu's velocity distribution equation. $J$. Hydrologic Engrg., ASCE, 9(1), 42-50.

Muste, M. and Patel, V. C. (1997). Velocity profiles for particles and liquid in open-channel flow with suspended sediment. J. Hydr. Engrg., ASCE, 123(9), 742-751. 
Junke Guo and Pierre Y. Julien / JAFM , Vol. 1, No. 2, pp. 17-23, 2008.

Nezu, I., Tominaga, A. and Nakagawa, H. (1993). Field measurements of secondary currents in straight rivers. J. Hydr. Engrg., ASCE, 119(5), 598-614.

Nezu, I. and Rodi, W. (1986). Open-channel flow measurements with a Laser Doppler Anemometer. $J$. Hydr. Engrg., ASCE, 112(5), 335-355.

Sarma, K. V. N., Lakshminarayana, P., and Rao, N. S. L. (1983). Velocity distribution in smooth rectangular open-channels., J. Hydr. Engrg., ASCE, 109(2), 271289.
Sarma, K. V. N., Prasad, B. V. R. and Sarma, A. K. (2000). Detailed study of binary law for open channels. J. Hydr. Engrg., ASCE, 126(3), 210-214.

Steffler, P. M. Rajaratnam, N. and Peterson, A. W. (1985). LDA measurement in open channel. J. Hydr. Eng., ASCE, 111(1), 119-130. 